\title{
The Tetraspanin CD37 Protects Against Glomerular IgA Deposition and Renal Pathology
}

Angelique L. Rops, ${ }^{*}$ Carl G. Figdor, ${ }^{\dagger}$

Alie van der Schaaf, ${ }^{\dagger}$ Wim P. Tamboer, ${ }^{*}$

Marinka A. Bakker, ${ }^{*}$ Jo H. Berden, ${ }^{*}$

Henry B.P.M. Dijkman, ${ }^{\ddagger}$ Eric J. Steenbergen, ${ }^{\ddagger}$ Johan van der Vlag, ${ }^{*}$ and Annemiek B. van Spriel ${ }^{\dagger}$

From the Nephrology Research Laboratory and Department of Nephrology,* and the Departments of Tumor Immunology, ${ }^{\dagger}$ and Pathology, Nijmegen Centre for Molecular Life Sciences, Radboud University Nijmegen Medical Centre, Nijmegen, The Netherlands

The tetraspanin protein CD37 is a leukocyte-specific transmembrane protein that is highly expressed on $B$ cells. CD37-deficient $\left(\mathrm{CD}^{-1-} 7^{-/}\right)$mice exhibit a 15-fold increased level of immunoglobulin A (IgA) in serum and elevated numbers of $\mathrm{IgA}^{+}$plasma cells in $1 \mathrm{ym}$ phoid organs. Here, we report that $\mathrm{CD} 37^{-1-}$ mice spontaneously develop renal pathology with characteristics of human IgA nephropathy. In young naive $\mathrm{CD} 7^{-/-}$mice, mild IgA deposition in glomeruli was observed. However, $\mathrm{CD} 37^{-/-}$mice developed high titers of IgA immune complexes in serum during aging, which was associated with increased glomerular IgA deposition. Severe mesangial proliferation, fibrosis, and hyalinosis were apparent in aged $\mathrm{CD} 37^{-/-}$ mice, whereas albuminuria was mild. To further evaluate the role of $\mathrm{CD} 37$ in glomerular disease, we induced anti-glomerular basement membrane (GBM) nephritis in mice. $\mathrm{CD}^{-1-}$ mice developed higher IgA serum levels and glomerular deposits of anti-GBM IgA compared with wild-type mice. Importantly, glomerular macrophage and neutrophil influx was significantly higher in $\mathrm{CD}^{-1-}$ mice during both the heterologous and autologous phase of anti-GBM nephritis. Taken together, tetraspanin CD37 controls the formation of IgA-containing immune complexes and glomerular IgA deposition, which induces influx of inflammatory myeloid cells. Therefore, CD37 may protect against the development of IgA nephropathy. (Am J Pathol 2010, 176:2188-2197; DOI: 10.2353/ajpath.2010.090770)
Tetraspanins are small four-transmembrane spanning proteins that are expressed on all nucleated cells. Tetraspanins associate noncovalently with (immuno-)receptors, signaling molecules, and each other, whereby they create 'tetraspanin microdomains,' also known as the tetraspanin web. ${ }^{1-3}$ These domains bring together receptors and signaling molecules into functional complexes. Consequently, tetraspanins are important in several fundamental cellular processes including migration, proliferation, differentiation, and cancer. ${ }^{4-6}$

In the immune system, tetraspanins have been reported to interact with antigen-presenting major histocompatibility complex molecules, integrins, and C-type lectins. $^{7,8}$ The importance of tetraspanins in immunology has been validated by recent studies with tetraspanindeficient mice. ${ }^{8}$ Tetraspanin CD37 has a rather confined expression; whereas the majority of tetraspanins (CD9, CD63, CD81, CD151, among others) have a broad tissue expression, CD37 is only expressed on cells of the immune system. CD37 is present on lymphocytes, monocytes, macrophages, neutrophils, and immature dendritic cells, with highest expression on B cells. ${ }^{9}$

CD37 associates with other tetraspanins (CD53, CD81, and CD82), major histocompatibility complex class II molecules, and the $\beta$-glucan receptor dectin-1. ${ }^{9,10}$ CD37-deficient mice $\left(\mathrm{CD} 37^{-1-}\right)$ display defects in various arms of the immune system, including impaired antibody responses, $\mathrm{T}$ cell hyperproliferation, and increased antigen-presenting capacity by dendritic cells. ${ }^{11-13}$ Recently, we observed that tetraspanin protein CD37 inhibits immunoglobulin ( $\lg A)$ responses both in steady-state conditions and during infection. ${ }^{14} \mathrm{CD} 37^{-1-}$ mice exhibit a 15 -fold increased level of $\lg \mathrm{A}$ in serum and significantly elevated numbers of $\lg \mathrm{A}^{+}$ plasma cells in lymphoid organs.

Supported in part by the Dutch Cancer Society (KWF Kankerbestrijding grant 2007-3917, to A.v.S.), the Netherlands Organization for Scientific Research (NWO Aard-en Levenswetenschappen to A.v.S.), and the Dutch Kidney Foundation (grant C05.2152, to A.R.).

Accepted for publication January 12, 2010

Address reprint requests to Dr. Annemiek B. van Spriel, Department of Tumor Immunology, Nijmegen Centre for Molecular Life Sciences (278) TIL, Radboud University Nijmegen Medical Centre, Postbox 9101, 6500HB, Nijmegen, The Netherlands. E-mail: avansprie|@scientist.com. 
Immunoglobulin A is critical for protecting the host from environmental and microbial infections. However, systemic IgA overproduction has been linked to IgA deposition in the kidney and development of IgA nephropathy (IgAN; Berger's disease). ${ }^{15}$ The special characteristics of IgA antibodies in serum of IgAN patients (predominantly polymeric $\lg \mathrm{A}_{1}$, lambda light chains, and aberrant O-glycosylation) promote IgA immune complex formation and mesangial deposition, but the precise molecular mechanisms underlying IgAN remain unclear. ${ }^{16,17}$ The high levels of circulating IgA antibodies in CD37 ${ }^{-1-}$ mice stimulated us to investigate the possible involvement of CD37 in the development of IgAN and experimental nephritis. The model of anti-glomerular basement membrane (GBM) nephritis is induced by injection of heterologous anti-GBM antibodies, which bind immediately to the GBM. This initiates complement activation and deposition resulting in leukocyte attraction and inflammation. During the acute heterologous phase, glomerular polymorphonuclear neutrophil (PMN) influx peaks 2 hours after injection, whereas albuminuria is manifested from 1 day on. ${ }^{18-21}$

We report that $\mathrm{CD} 37^{-1-}$ mice spontaneously develop high titers of IgA immune complexes in serum, glomerular IgA deposition, and mesangial proliferation, which are the hallmarks of IgAN. ${ }^{16}$ Moreover, tetraspanin CD37 controls glomerular IgA deposition and influx of inflammatory myeloid cells during anti-GBM nephritis. Taken together, the B cell protein CD37 controls glomerular IgA deposition and may be protective against the development of IgA nephropathy.

\section{Materials and Methods}

\section{Mice}

CD37-deficient $\left(\mathrm{CD} 37^{-1-}\right)$ mice on a C57BL/6J background and age- and sex-matched C57BL/6J wild-type mice (Charles River, France) were bred at the Central Animal Laboratory (Radboud University Nijmegen, The Netherlands) and handled according to the guidelines of the local animal ethics committee. For aging studies, groups of twelve $\mathrm{CD} 37^{-1-}$ and wild-type mice were matured in the same room and used at the age of 1 or 1.5 years.

\section{Immunoglobulin A Western Blot Analysis}

Serum (1, 0.05, or $0.001 \mu \mathrm{l}$ ) was loaded on 8\% SDS-PAGE gels, separated under nonreducing conditions, and blotted onto PVDF membranes. Membranes were blocked in PBS, $3 \%$ bovine serum albumin, $1 \%$ skim milk powder at $4^{\circ} \mathrm{C}$ overnight, and probed with biotinylated rat anti-mouse IgA (BD Pharmingen, San Diego, CA), followed by coupled streptavidin-horseradish peroxidase (Invitrogen Life Technologies, Breda, The Netherlands) and enhanced luminescence detection kit (Pierce, Rockford, IL).

\section{Immunofluorescence Staining}

Cryosections ( $4 \mu \mathrm{m}$ ) were fixed in ice-cold acetone for 10 minutes and incubated with $5 \mu \mathrm{g} / \mathrm{ml}$ primary antibodies diluted in PBS containing $1 \%$ bovine serum albumin (Sigma-Aldrich Chemie, Zwijndrecht, The Netherlands) and $0.05 \%$ sodium azide (IF-buffer) for 45 minutes at room temperature. Directly labeled antibodies included biotinylated rat anti-mouse IgA (BD Pharmingen), goat antimouse $\mathrm{C} 3 \mathrm{c}-$ and fibrinogen-fluorescein isothiocyanate (FITC; Nordic, Tilburg, The Netherlands), goat anti-rabbit IgG-Alexa 488, goat anti-mouse IgM-, IgG- $(\mathrm{H}+\mathrm{L})$, IgG1-, and IgG2a-Alexa 488, and goat anti-rat Alexa 488 (Invitrogen Life Technologies, Breda, The Netherlands). Unlabeled antibodies included anti-mouse GR-1 (RB6.8C5), CD4 (L3T4), CD8a (Ly-2; all from BD Biosciences, Alphen aan de Rijn, The Netherlands), CD68 (MCA1957; Serotec, Oxford, United Kingdom), and goat anti-mouse lambda light chain (Serotec). Sections were washed in PBS and incubated with the appropriate secondary Alexa 488 antibodies in IF-buffer for 45 minutes at room temperature. Glomeruli were visualized using the hamster anti-agrin antibody (MI91) ${ }^{22}$ followed by a Cy3-labeled antibody (Jackson ImmunoResearch Laboratories Inc., West Grove, PA). Finally, sections were postfixed with $1 \%$ paraformaldehydePBS and embedded in VectaShield mounting medium H-1000 (Brunschwig Chemie, Amsterdam, The Netherlands). The amount of rabbit $\lg \mathrm{A}$ or mouse $\lg \mathrm{A}, \lg \mathrm{M}$, $\lg \mathrm{g}$, IgG1, and IgG2a deposited in glomeruli was quantified by titrating the appropriate secondary antibodies. The titer was defined as the reciprocal of the dilution that was still positive and expressed as arbitrary units (AU). The staining intensities of all antibodies were scored in 50 glomeruli on a scale between 0 and $10(0=$ no staining, $1=10 \%$ staining intensity, with a maximum score of 10 for $100 \%$ staining intensity).

\section{Renal Histology}

Renal sections ( $5 \mu \mathrm{m})$ were deparaffinized, rehydrated, and stained with Periodic acid-Schiff, Chromotrop Anilinblue, and Jones' methenamine. Sections were counterstained with hematoxylin. Sections were evaluated by an experienced pathologist. At least 30 glomeruli were analyzed for presence of mesangial proliferation, crescents, hyalinosis, and sclerosis. Mesangial proliferation was scored as absent ( $\leq 3$ mesangial cells/area), mild (4 to 5 mesangial cells/ area), moderate (6 to 7 mesangial cells/area), or severe ( $\geq 8$ mesangial cells/area). ${ }^{23}$

\section{Transmission Electron Microscopy}

For electron microscopy, kidneys were fixed in 2.5\% glutaraldehyde dissolved in $0.1 \mathrm{M}$ sodium cacodylate buffer $\left(\mathrm{pH} \mathrm{7.4)}\right.$ overnight at $4^{\circ} \mathrm{C}$ and washed in the same buffer. Tissues were postfixed in palade-buffered $2 \%$ OsO4 for 1 hour, dehydrated, and embedded in Epon812 according to the Luft procedure (Merck, Darmstadt, Germany). Ultrathin sections were contrasted with $4 \%$ uranyl acetate for 45 minutes and subsequently with lead citrate 
for 5 minutes at room temperature. Sections were examined in a Jeol 1200 EX2 electron microscope (JEOL, Tokyo, Japan).

\section{Detection of IgA Immune Complexes in Serum}

MaxiSorp 96-wells plates (Nunc, Roskilde, Denmark) were coated with $2 \mu \mathrm{g} / \mathrm{ml}$ rat anti-mouse IgG1 or IgG2a (BD Pharmingen) overnight at $4^{\circ} \mathrm{C}$. Plates were washed with $0.05 \%$ Tween/PBS, blocked with $2 \%$ milk/PBS, and serial dilutions of mouse sera were incubated for 1 hour at room temperature. Subsequently, wells were washed and incubated with $1 \mu \mathrm{g} / \mathrm{ml}$ biotin-conjugated rat anti-mouse IgA (BD Pharmingen) in $0.2 \%$ milk/PBS for 1 hour at room temperature followed by streptavidin-horseradish peroxidase (Invitrogen) and tetramethylbenzidine substrate (SFRI Laboratories, Berganton, France). The reaction was stopped with $2 \mathrm{M} \mathrm{H}_{2} \mathrm{SO}_{4}$, and adsorption was measured at $450 \mathrm{~nm}$ using a Bio-Rad Multiplate Reader (BioRad Laboratories, Veenendaal, The Netherlands).

\section{Induction of Anti-GBM Glomerulonephritis and Determination of Albuminuria}

Experimental anti-GBM nephritis was induced as described. ${ }^{21}$ Briefly, groups of five wild-type and CD37 ${ }^{-1-}$ mice (14 to 18 weeks old) were injected in the tail vein

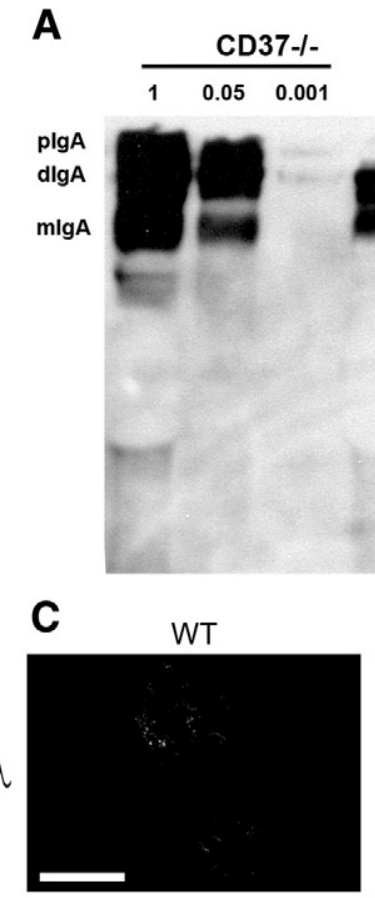

D
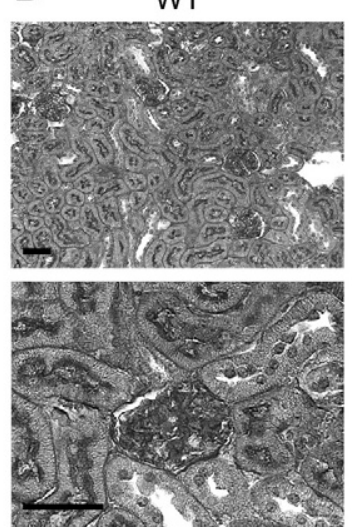

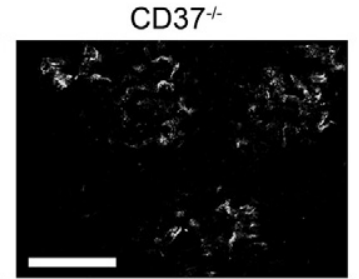

CD37-

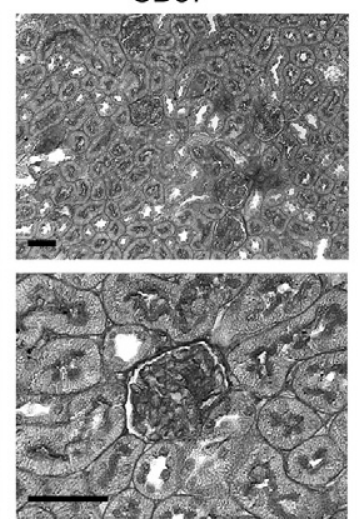

B
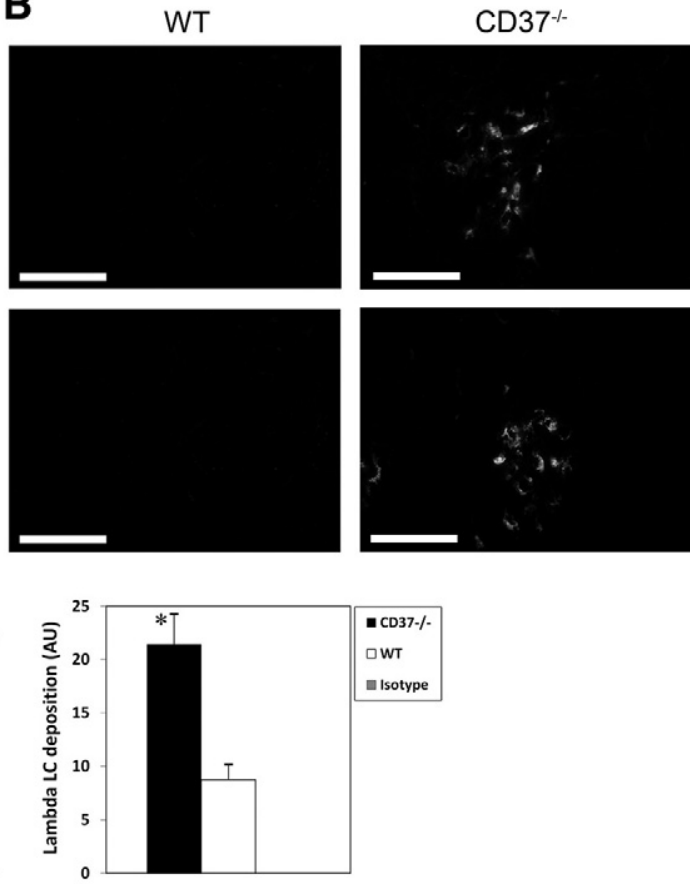

E

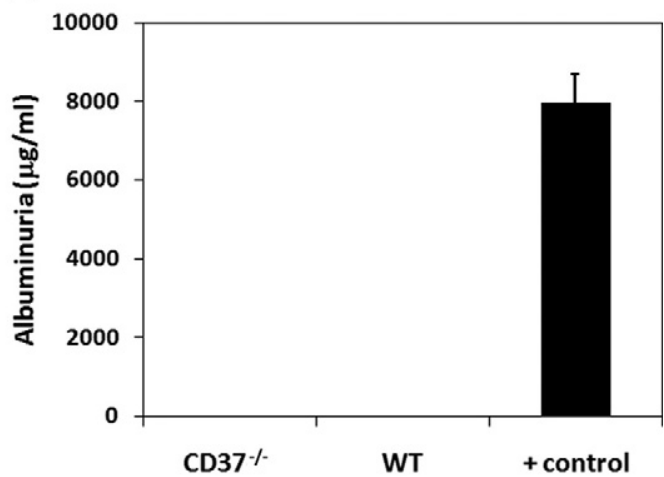

Figure 1. IgA deposition in glomeruli of young $\mathrm{CD} 37^{-/-}$mice. A: Characterization of molecular forms of $\operatorname{IgA}(\mathrm{m}=$ monomeric, $\mathrm{d}=\mathrm{dimeric}, \mathrm{p}=\mathrm{polymeric}$ IgA) in serum of naïve 3-month-old wild-type and $\mathrm{CD} 37^{-1-}$ mice. $1,0.05$, or $0.001 \mu \mathrm{l}$ of serum was loaded on $8 \%$ SDS-PAGE gels, and Western blots were probed with anti-mouse IgA. Note the predominance of high molecular weight IgA (pIgA) in CD37 ${ }^{-1-}$ serum. B: Kidneys of 3-month-old wild-type (left) and CD37 ${ }^{-/-}$(right) mice were stained for presence of IgA by immunohistochemistry. Scale bars represent $50 \mu \mathrm{m}$. C: Immunohistochemistry stainings of lambda light chains in kidneys of wild-type and $\mathrm{CD} 37^{-1-}$ mice. Scale bars represent $50 \mu \mathrm{m}$. Quantification of lambda light chain deposits in glomeruli of $\mathrm{CD} 37^{-1-}$ mice as compared with wild-type mice $\left({ }^{*} P<\right.$ 0.01 ) as described in Materials and Methods (right). Isotype stainings were negative. AU indicates arbitrary units. D: Histological analysis of kidneys (Periodic acid-Schiff staining) of young wild-type (left) and $\mathrm{CD}^{-1-}$ (right) mice did not reveal any abnormalities. Scale bars represent $60 \mu \mathrm{m}$. E: Albuminuria was not detected in young wild-type and $\mathrm{CD} 37^{-/-}$mice by Mancini test. Urine of mice with anti-GBM nephritis was used as positive $(+)$control. 
with 1,3 , or 8 mg purified rabbit IgG anti-mouse GBM in sterile PBS. Urine was collected and mice were killed after 2 hours and 4 days. Blood was taken for antibody analysis (described below), and kidneys were fixed in $10 \%$ buffered formalin and paraffin embedded or snapfrozen in liquid nitrogen for histology and immunohistochemistry, respectively. Albumin in urine was measured by radial immunodiffusion (Mancini).

\section{Determination of Serum Levels of Mouse IgA, IgG, IgG1, and IgG2a Anti-Rabbit IgG Antibodies during Anti-GBM Nephritis}

Serum levels of mouse antibodies directed against rabbit IgG were determined by ELISA as described. ${ }^{21}$ Briefly, 96-wells plates were coated with $10 \mu \mathrm{g} / \mathrm{well}$ rabbit IgG. Serial dilutions of mouse plasma from wild-type and $\mathrm{CD} 37^{-1-}$ mice with anti-GBM nephritis were added, and anti-rabbit antibodies were detected by peroxidase-conjugated goat anti-mouse IgG, IgG1, IgG2a (Sanbio BV, Uden, The Netherlands), or biotin-conjugated goat antimouse IgA, followed by streptavidin-horseradish peroxidase and tetramethylbenzidine substrate.

\section{Purification of Mouse IgA and Adoptive Transfer Experiments}

IgA was purified from pooled sera of twelve CD37 $7^{-1-}$ mice by affinity chromatography. Rabbit anti-mouse IgA ( $\alpha$ chain; Abnova $\mathrm{GmbH}$, Heidelberg, Germany; $9 \mathrm{mg}$ ) was coupled to cyanogen bromide-activated (CNBr) Sepharose 4B. The column was first absorbed with pooled wild-type serum to block nonspecific binding. Subsequently, pooled $\mathrm{CD} 37^{-1-}$ serum was applied to the column, bound IgA was eluted in a $0.05 \mathrm{M}$ citrate $(\mathrm{pH}$ 2.6)/1 M NaCl/0.5 M acetate ( $\mathrm{pH} 3.0$ ) buffer, neutralized, and concentrated. IgA was sterilized through $0.2 \mu \mathrm{m}$ filter before in vivo use. Wild-type mice (14 to 18 weeks old; $n=3$ ) were injected in the tail vein with $0.9 \mathrm{mg}$ purified mouse IgA and $3 \mathrm{mg}$ rabbit anti-mouse GBM IgG. Control wild-type and $\mathrm{CD} 37^{-1-}$ mice (14 to 18 weeks old) were injected with $3 \mathrm{mg}$ rabbit anti-mouse GBM IgG only. Mice were killed after 4 days, and kidneys were processed for immunohistochemistry as described above.

\section{Statistical Analysis}

Values are expressed as means \pm SEM and significance was evaluated by Student $t$ test using GraphPad Prism (GraphPad Software Inc., San Diego, CA).

\section{Results \\ CD37-Deficiency Leads to Glomerular IgA Deposition}

The high levels of circulating IgA antibodies in $\mathrm{CD} 37^{-/-}$ mice ${ }^{14}$ stimulated us to investigate the possible involvement of CD37 in the development of IgAN. Because the circulating IgA antibodies in IgAN patients that promote mesangial deposition have special characteristics (ie, predominantly polymeric IgA, lambda light chains, and aberrant O-glycosylation), ${ }^{16}$ we first analyzed the properties of IgA in CD37 ${ }^{-1-}$ serum at the protein level. CD37 $7^{-1-}$ serum contained mainly polymeric IgA, whereas IgA in wild-type serum was predominantly present as dimeric and monomeric forms (Figure 1A). Next, we evaluated glomerular IgA deposition - the hallmark of IgAN - and renal histology in wildtype and $\mathrm{CD} 37^{-1-}$ mice of different ages. All evaluated young $\mathrm{CD} 37^{-1-}$ mice (3 months old) showed clear mesangial deposition of mouse IgA in glomeruli, in contrast to none of wild-type mice (Figure 1B) as detected by immunohistochemistry. Moreover, lambda light chains were readily detected in glomeruli of CD37 ${ }^{-1-}$ mice (Figure $1 C$ ). Quantification revealed that glomeruli of $\mathrm{CD} 37^{-1-}$ mice contained significantly more lambda light chain deposition than glomeruli of wild-type mice (21.5 versus $8.8 \mathrm{AU} ; P<$ $0.01)$. However, renal histology did not reveal abnormalities in these young $\mathrm{CD} 37^{-1-}$ mice (Figure 1D). Furthermore, these mice presented no albumin in the urine (Figure 1E).

\section{CD37-Deficiency Leads to Severe Renal Pathology During Aging}

In contrast to young $\mathrm{CD} 37^{-1-}$ mice, 1.5 -year-old mice developed mild albuminuria (Figure 2A) without hematuria (data not shown). Although statistically not significant, the urinary albumin excretion in aged CD37 $7^{-1-}$ mice tended to be higher compared with aged-matched wild-type mice. Kidneys of aged $\mathrm{CD} 37^{-1-}$ mice showed intense glomerular IgA deposition in contrast to kidneys of aged wild-type mice, as revealed by immunohistochemistry (Figure 2B). These results indicate that, normally, tetraspanin CD37 controls glomerular IgA deposition. Glomerular IgM and IgG depositions were similar in the young and aged CD37 $7^{-1-}$ and wild-type mice (data not shown). It has been shown that serum IgA-IgG2a immune complex levels correlate with the severity of glomerular lesions in a mouse model of IgAN ${ }^{24}$ IgA-containing immune complexes are also involved in the pathogenesis of IgAN in humans. ${ }^{16}$ Therefore, we evaluated the IgA-containing immune complex levels in serum of $\mathrm{CD} 37^{-1-}$ mice. Interestingly, aged CD37 ${ }^{-1-}$ mice had significantly higher serum IgA-IgG1 and IgA-IgG2a immune complex levels compared with young $\mathrm{CD} 37^{-1-}$ and wildtype (both young and aged) mice (Figure $2 \mathrm{C}$ ), supporting a role for IgA immune complexes in driving mesangial deposition in $\mathrm{CD} 37^{-1-}$ mice. Next, kidneys of aged $\mathrm{CD} 37^{-1-}$ and wild-type mice were analyzed for the presence of histological lesions. All kidneys of aged $\mathrm{CD} 37^{-1-}$ mice showed histological abnormalities with prominent mesangial expansion attributable to mesangial hypercellularity, hyperlobulation, frequent mesangiolysis, and prominent endocapillary hyalinosis (Figure 2, D-F). As a consequence, glomeruli were enlarged and clear matrix deposition was observed (Figure 2F). Crescents were not detected in glomeruli of aged $\mathrm{CD} 37^{-1-}$ mice. Interstitial fibrosis and occasional segmental adhesions with mild hyperplasia of the parietal epithelium were also observed (Figure 2, D-F). Quantifica- 
A

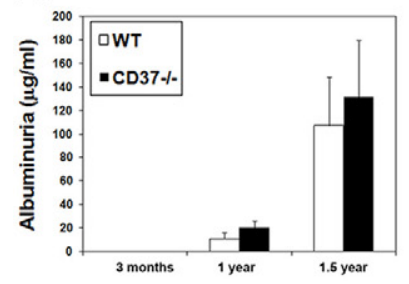

C
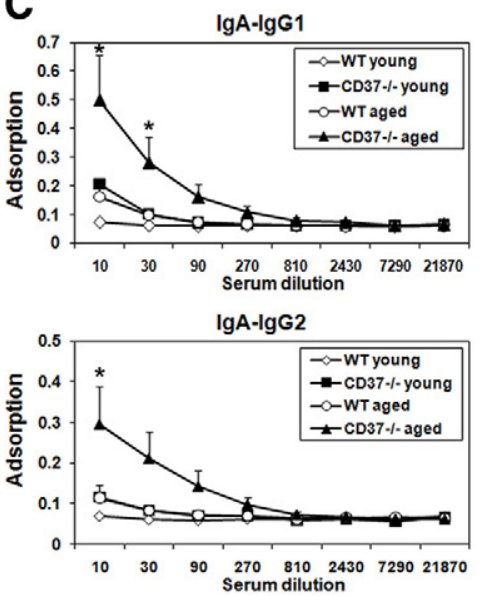

E
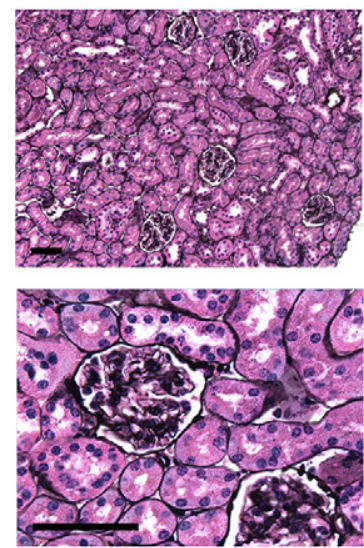

G

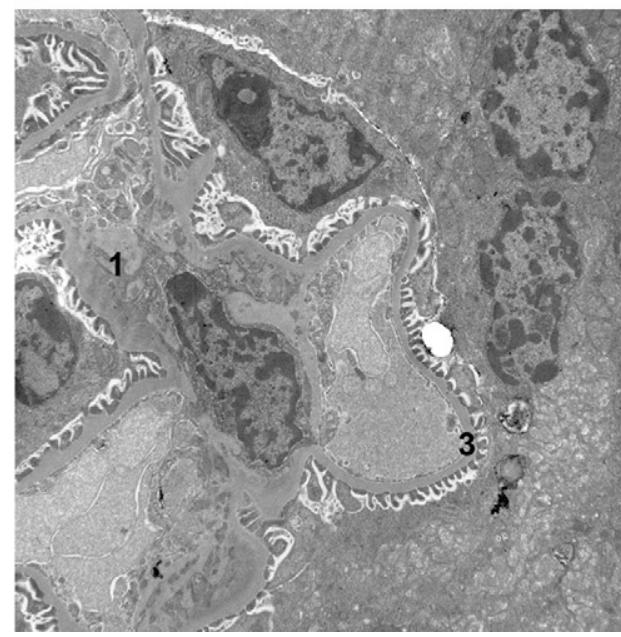

B $\quad$ WT

WT

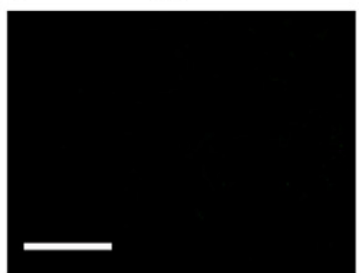

D WT
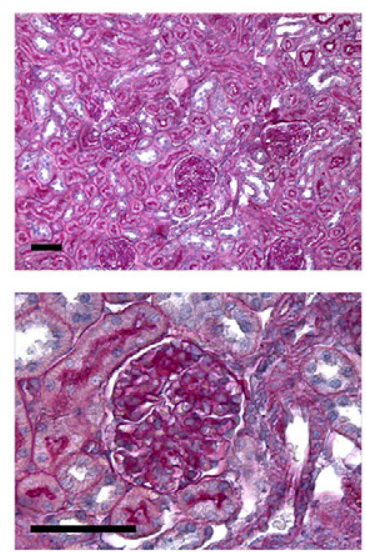

CD37-
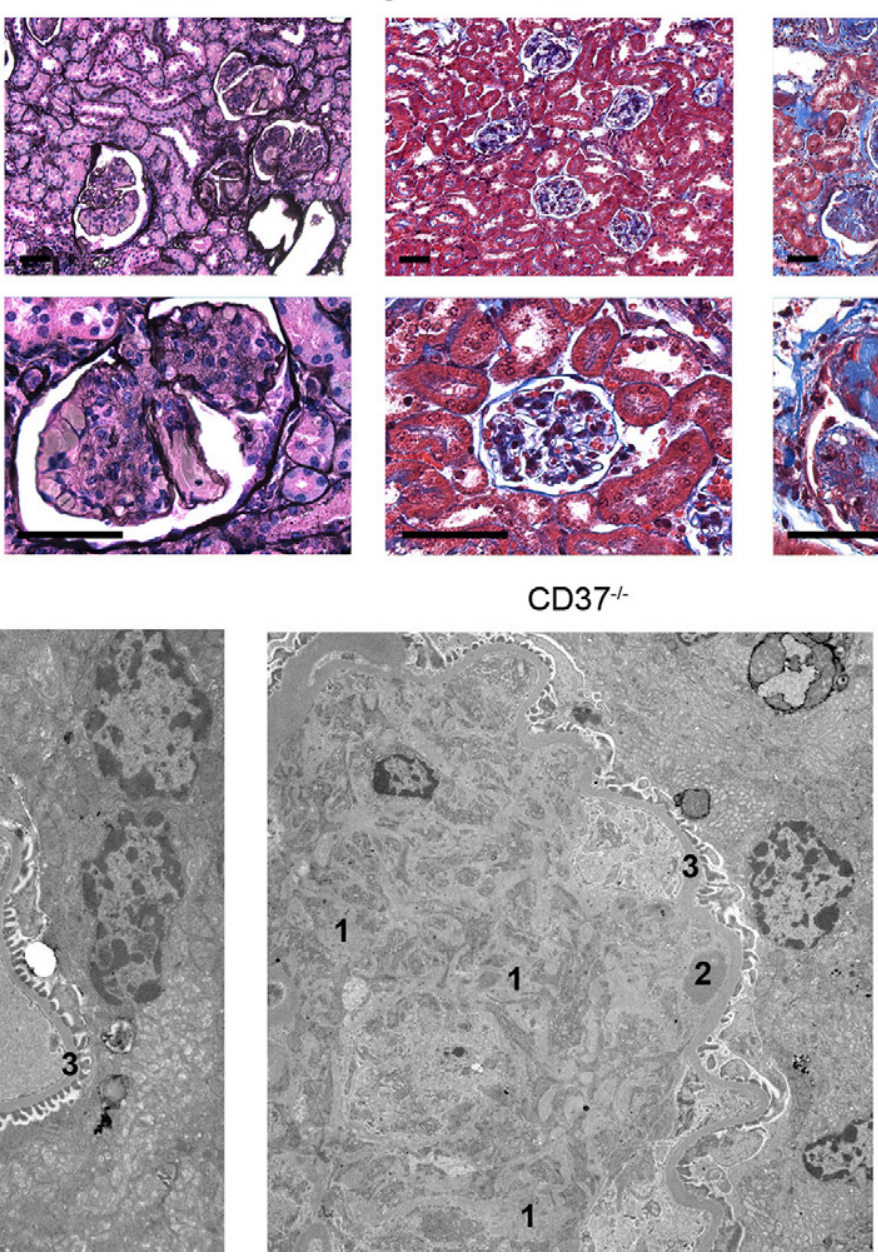

$\mathrm{CD} 37^{\cdots}$
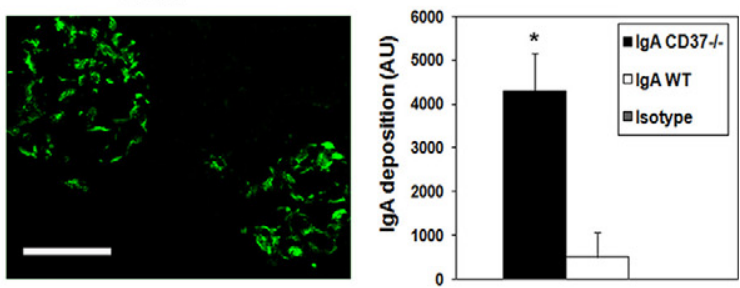

CD37-1-
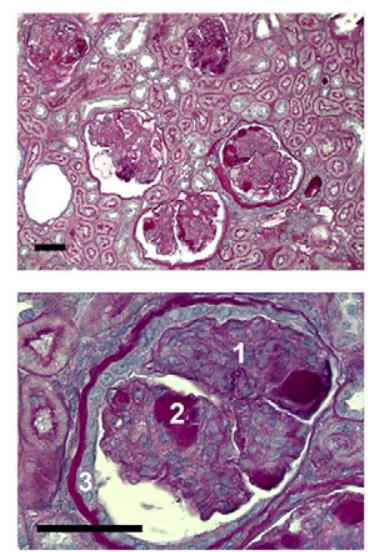

F WT
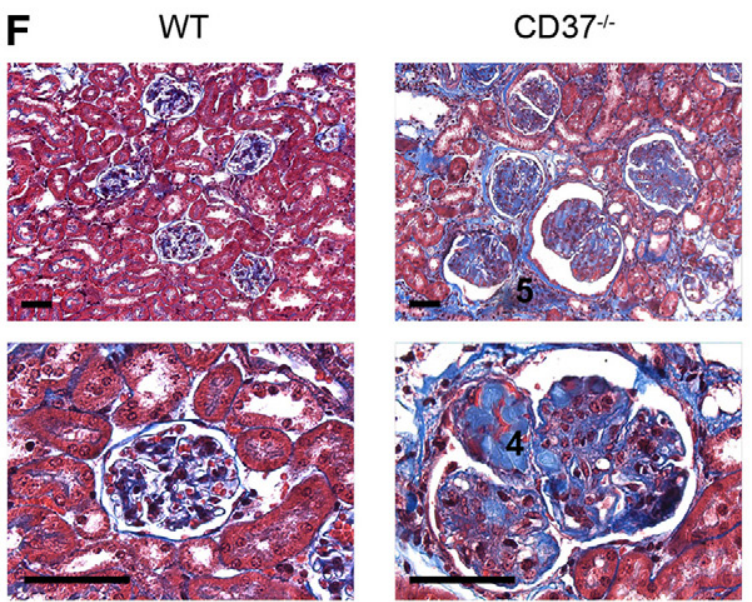
tion revealed that all CD37 ${ }^{-1-}$ kidneys demonstrated moderate/severe mesangial proliferation that was present in $62.5 \%( \pm 19.6 \%)$ of the evaluated glomeruli. Hyalinosis was observed in $50 \%$ of the $\mathrm{CD} 37^{-1-}$ kidneys and in $33.9 \%$ ( \pm $18.4 \%$ ) of the glomeruli. None of these lesions were found in kidneys of aged-matched wild-type mice. Electron microscopy of kidneys of aged CD37 $7^{-1-}$ mice showed severe mesangial expansion and hypercellularity with scattered small electron-dense deposits (Figure 2G). There was frequent mesangiolysis with microaneurysm formation without any endothelial abnormalities, excluding thrombotic microangiopathy as the cause of mesangiolysis. There was occasional subendothelial hyalinosis. The glomerular basement membrane was unremarkable, and podocytes showed normal foot processes (Figure 2G). Kidneys of aged-matched wild-type mice did not demonstrate abnormalities except for some electron-dense deposits in mesangial cells that was attributable to IgG/IgM deposition (data not shown), but not attributable to IgA deposition (Figure 2B). Taken together, these results demonstrate that $\mathrm{CD} 37^{-1-}$ mice spontaneously develop renal pathology with evident glomerular IgA deposition and mesangial proliferation.

\section{CD37 ${ }^{-1-}$ Mice Develop High Levels of Mouse IgA Anti-Rabbit IgG and More Glomerular IgA Deposits during Anti-GBM Nephritis}

Because IgAN is triggered under inflammatory conditions, ${ }^{25}$ we determined whether young $\mathrm{CD} 37^{-1-}$ were more prone to renal damage by induction of anti-GBM nephritis in $\mathrm{CD}_{3} 7^{-1-}$ and wild-type mice. Inflammation was analyzed during the acute heterologous phase (ie, after 2 hours) and during the autologous phase (ie, after 4 days). ${ }^{21}$ Administration of $8 \mathrm{mg}$ rabbit anti-mouse GBM antibodies to wild-type and $\mathrm{CD} 37^{-1-}$ mice resulted in similar binding of rabbit IgG along the GBM after 2 hours (Figure 3A), which remained unaffected until 4 days. Evaluation of serum levels of mouse antibodies directed against rabbit IgG revealed significantly higher levels of serum mouse IgA anti-rabbit IgG in $\mathrm{CD} 37^{-1-}$ mice compared with wild-type mice at day 4 after induction of anti-GBM nephritis (Figure 3B). $\mathrm{CD} 37^{-1-}$ mice also showed higher serum levels of mouse IgG anti-rabbit lgG compared with wild-type mice after 4 days (data not shown). Furthermore, CD37 ${ }^{-1-}$ mice demonstrated significantly higher IgA-IgG1 and IgA-IgG2a immune complex levels in serum compared with wild-type mice at day
4 after induction of nephritis (Figure 3C). The glomerular rabbit IgG binding was accompanied by a linear complement (C3c) deposition in both mice strains after 2 hours (Figure 4A). During the autologous phase of the disease, CD37 ${ }^{-1-}$ mice developed more glomerular deposits of mouse IgA anti-GBM compared with wild-type mice as revealed by immunohistochemistry (Figure 4B). Quantification of the glomerular deposition confirmed that $\mathrm{CD} 37^{-1-}$ mice showed significantly more glomerular mouse IgA deposition compared with wild-type mice for all injected doses evaluated $(1,3$, or $8 \mathrm{mg}$ ) of rabbit anti-GBM IgG (Figure 4C). IgG deposition along the capillary wall was comparable between $\mathrm{CD} 37^{-1-}$ and wild-type mice. The administration of rabbit antiGBM IgG showed a dose-dependent effect on the glomerular IgA deposition. Thus, CD37-deficiency increases specific IgA deposition in glomeruli during experimental nephritis.

\section{CD37-Deficiency Leads to Increased Glomerular PMN and Macrophage Influx During Anti-GBM Nephritis}

Next, we evaluated the glomerular leukocyte influx, being one of the key determinants of glomerular damage in glomerulonephritis. ${ }^{26}$ During anti-GBM nephritis, PMNs and macrophages emerge within hours, whereas CD4 ${ }^{+}$ and $\mathrm{CD} 8^{+} \mathrm{T}$ cells influx is observed after a few days. ${ }^{21}$ We observed glomerular PMN influx to be significantly higher in CD37 ${ }^{-1-}$ mice compared with wild-type mice 2 hours after injection of anti-GBM IgG (Figure 5A). The glomerular influx of macrophages, $\mathrm{CD}^{+}$, and $\mathrm{CD}^{+} \mathrm{T}$ cells was similar between $\mathrm{CD} 37^{-1-}$ and wild-type mice after 2 hours. However, after 4 days both residual glomerular PMN and macrophage influx were significantly increased in $\mathrm{CD}_{3} 7^{-1-}$ mice compared with wild-type mice (Figure 5, B and C). As control, kidneys of naïve wild-type and $\mathrm{CD} 37^{-1-}$ mice were analyzed and did not stain positive for leukocytes, indicative for the absence of inflammation (data not shown). These results indicate that tetraspanin CD37 controls glomerular PMN and macrophage influx during anti-GBM nephritis. In contrast, the glomerular influx of $\mathrm{CD}^{+}$and $\mathrm{CD}^{+}{ }^{+}$T cells was not different between both mouse strains after 2 hours or 4 days. Surprisingly, CD37 $7^{-1-}$ mice did not show more albuminuria compared with wild-type mice after 4 days (Figure 5D). However, analysis of renal histology re-

\footnotetext{
Figure 2. Pronounced renal pathology in aged $\mathrm{CD} 37^{-/-}$mice. A: Development of mild albuminuria in wild-type and $\mathrm{CD} 37^{-/-}$mice during aging. B: Kidneys of 1.5 -year-old naive wild-type (left) and $\mathrm{CD} 37^{-1-}$ (middle) mice were stained for presence of IgA by immunohistochemistry. Scale bars represent $40 \mu \mathrm{m}$. Quantification of IgA deposition in glomeruli of $\mathrm{CD} 37^{-/-}$mice as compared with 1.5-year-old wild-type mice $\left({ }^{*} P<0.01\right)$ as described in Materials and Methods (right). Isotype staining was negative. AU indicates arbitrary units. C: Development of high titers of IgA-IgG1 (upper) and IgA-IgG2a (lower) immune complexes in serum of $\mathrm{CD} 37^{-/-}$mice detected by ELISA. Aged CD $37^{-/-}$mice (black triangles) contain significantly higher levels of IgA immune complexes in serum than young $\mathrm{CD} 37^{-/-}$mice (black squares) and wild-type (young and old) mice (white symbols; ${ }^{*} P<0.05$ ). Evident renal pathology in kidneys of 1.5 -year-old $\mathrm{CD} 37^{-/-}$mice visualized by Periodic acid-Schiff $(\mathbf{D})$, Jones' methenamine silver $(\mathbf{E})$, and Chromotrop Anilinblue $(\mathbf{F})$ staining. Note the presence of severe mesangial proliferation (1), hyalinosis (2), and prominent parietal epithelium (3) in CD $37^{-/-}$glomeruli (D). Matrix deposition (4) and interstitial fibrosis (5) in $\mathrm{CD}_{3} 7^{-1-}$ kidneys is visualized by Chromotrop Anilinblue staining (F). Kidneys of 1.5-year-old wild-type mice did not demonstrate abnormalities. Note that histology images of wild-type and $\mathrm{CD} 37^{-1-}$ kidneys of the same magnification are shown, demonstrating that $\mathrm{CD} 37^{-/-}$glomeruli are enlarged (Scale bars represent $60 \mu \mathrm{m})$. G: Electron microscopy of kidneys of 1.5 -year-old wild-type mice (left) and CD37 ${ }^{-1-}$ mice (right; $\left.\times 4000\right)$. Severe mesangial expansion with scattered electron-dense deposits (1) were observed in $\mathrm{CD} 37^{-/-}$glomeruli. Hyalinosis (2) was apparent whereas the glomerular basement membrane (3) was unaltered, and podocytes showed normal foot processes. Kidneys of aged wild-type mice did not demonstrate abnormalities except for some electron-dense deposits in the mesangial cells that was attributable to IgG/IgM deposition (data not shown) but not to IgA deposition (B).
} 
A

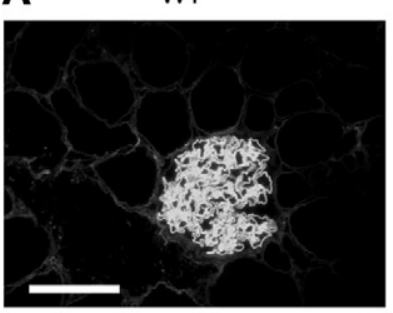

B

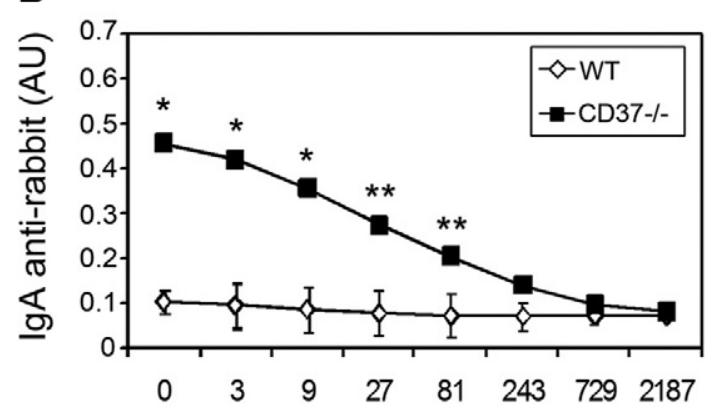

C
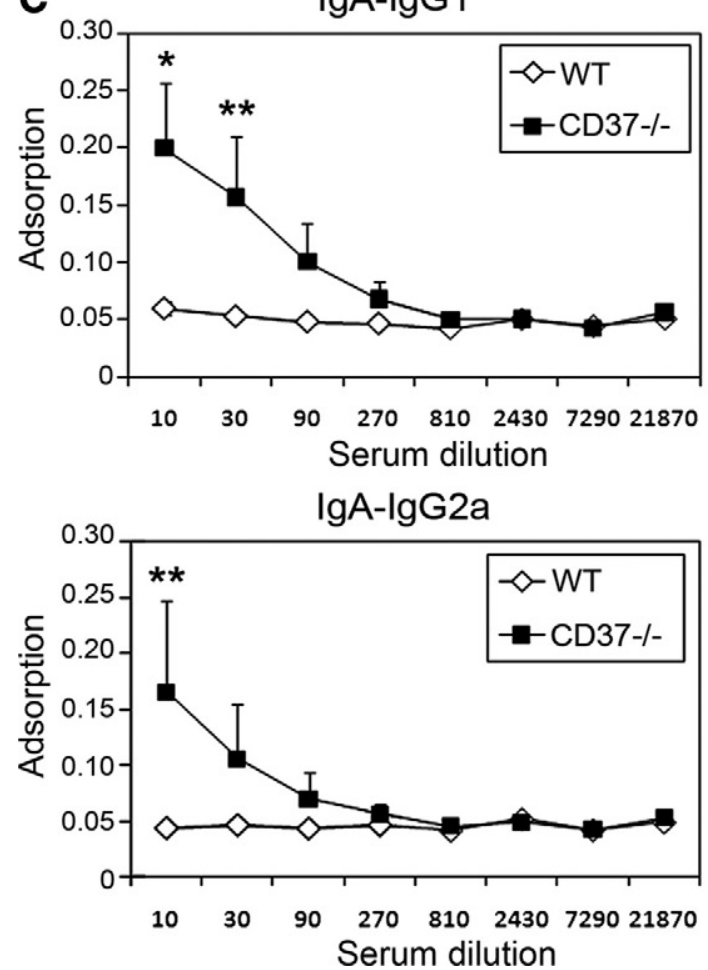

Figure 3. IgA response during anti-GBM nephritis in $\mathrm{CD} 37^{-/-}$versus wild-type mice. Anti-GBM nephritis was induced by injecting $8 \mathrm{mg}$ rabbit anti-GBM IgG i.v. Wild-type and CD $37^{-1-}$ kidneys were analyzed after 2 hours and 4 days. A: Deposition of rabbit IgG in glomeruli was similar between wild-type (left) and $\mathrm{CD}_{3} 7^{-\prime-}$ (right) mice analyzed by immunohistochemistry 2 hours after injection. Scale bars represent $50 \mu \mathrm{m}$. B: Serum of $\mathrm{CD} 37^{-/-}$and wild-type mice was analyzed for the presence of IgA directed against rabbit IgG 4 days after injection by ELISA $\mathrm{CD} 37^{-/-}$serum (black symbols) contains rabbit-specific IgA in contrast to wild-type serum (white symbols; ${ }^{*} P<0.001$, ${ }^{* * *} P<0.02$ ). AU indicates arbitrary units. C: Presence of IgA-IgG1 (upper) and IgA-IgG2a (lower) immune complexes in serum of $\mathrm{CD}_{3} 7^{-/-}$mice (black symbols), but not in serum of wild-type mice (white symbols), 4 days after induction of anti-GBM nephritis ( $\left.{ }^{*} P<0.02,{ }^{* * *} P<0.05\right)$.
A

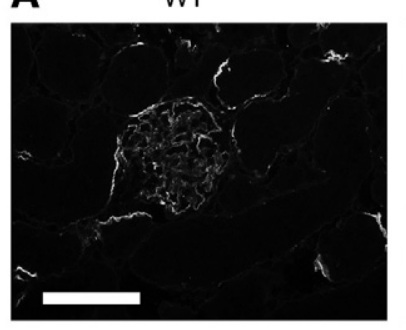

B
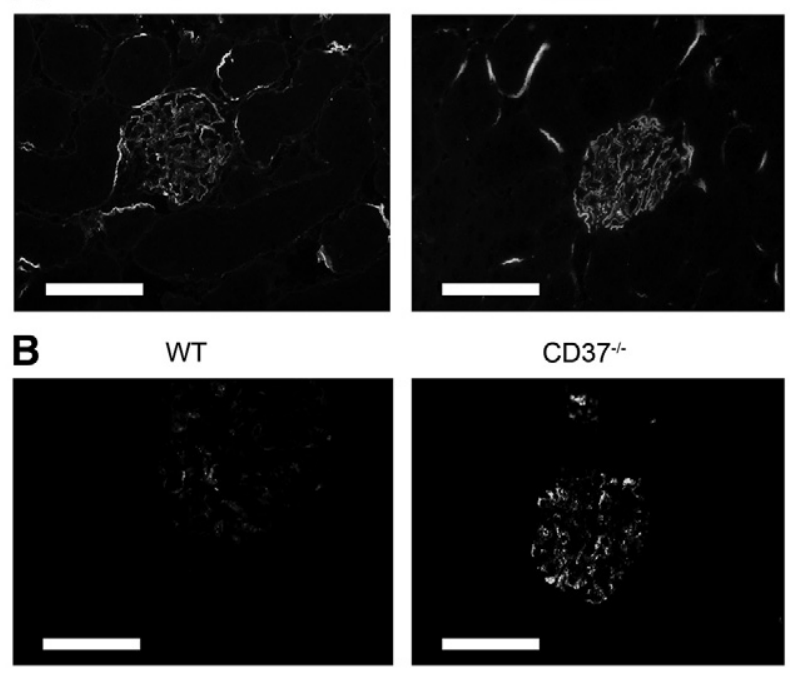

CD37

C
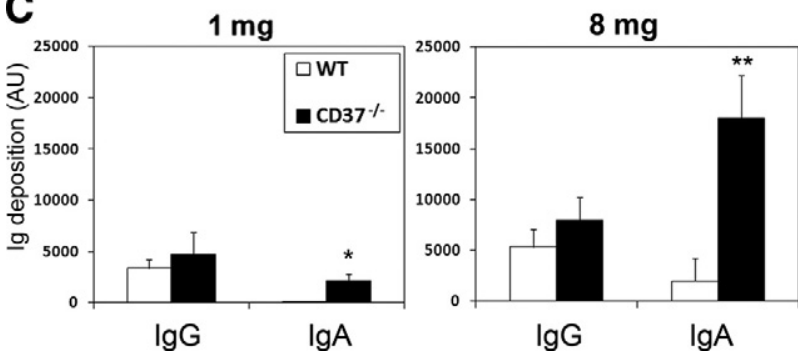

Figure 4. Increased IgA deposition into $\mathrm{CD} 37^{-/-}$glomeruli during antiGBM nephritis. Anti-GBM nephritis was induced by injecting 1, 3, and $8 \mathrm{mg}$ rabbit anti-GBM IgG i.v. in wild-type and $\mathrm{CD}^{-1} 7^{-1}$ mice. Kidneys were analyzed after 2 hours and 4 days. A: C3c complement deposition in glomeruli was similar between wild-type (left) and $\mathrm{CD}^{-1-}$ (right) mice analyzed by immunohistochemistry 2 hours after injection of $8 \mathrm{mg}$ anti-GBM. B: IgA deposition in wild-type (left) and $\mathrm{CD}_{3} 7^{-/-}$(right) glomeruli 4 days after injection of $8 \mathrm{mg}$ anti-GBM visualized by immunohistochemistry. Scale bars represent $50 \mu \mathrm{m}$. C: Quantification of IgA and IgG deposition in $\mathrm{CD}_{3} 7^{-1-}$ and wild-type glomeruli 4 days after administration of $1 \mathrm{mg}$ (left) and $8 \mathrm{mg}$ (right) anti-GBM. AU indicates arbitrary units. CD $37^{-1}$ glomeruli contain significantly more IgA deposition than wild-type glomeruli $\left({ }^{*} P<0.02,{ }^{* *} P<0.006\right)$

vealed moderate mesangial proliferation in $\mathrm{CD} 37^{-1-}$ glomeruli in contrast to wild-type glomeruli (Figure 5E).

To get more insight into the mechanism underlying the increased glomerular leukocyte influx in $\mathrm{CD} 37^{-1-}$ mice, we performed IgA adoptive transfer experiments. Purified IgA isolated from CD $37^{-1-}$ serum was injected intravenously into wild-type mice (0.9 mg lgA/mouse). Anti-GBM nephritis was induced in untreated (wild-type and $C D 37^{-1-}$ ) mice and in IgA-treated wild-type mice, and glomerular leukocyte influx was analyzed after 4 days. In line with Figure 5A, neutrophil and macrophage glomerular influx was significantly increased in CD37 ${ }^{-1-}$ mice compared with untreated wild-type mice. However, wild-type mice treated with IgA demonstrated leukocyte influx that was comparable with influx observed in glomeruli of CD37 ${ }^{-1-}$ mice (Figure 5F). These data indicate that elevated and deposited IgA by itself is sufficient to trigger leukocyte recruitment to glomeruli of $\mathrm{CD} 37^{-1-}$ mice. Thus, the tetraspanin CD37 controls the glomerular deposition of IgA that induces influx of inflammatory myeloid cells in vivo. 


\section{Discussion}

Systemic IgA overproduction has been linked to IgA deposition in the kidney and development of IgAN, ${ }^{15}$ how-

A

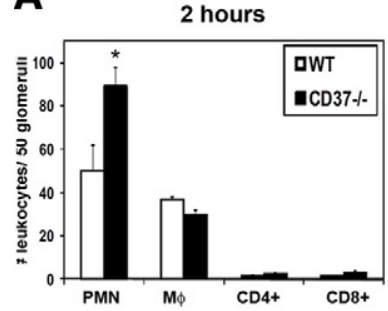

C WT

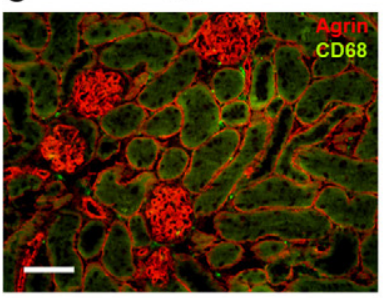

D

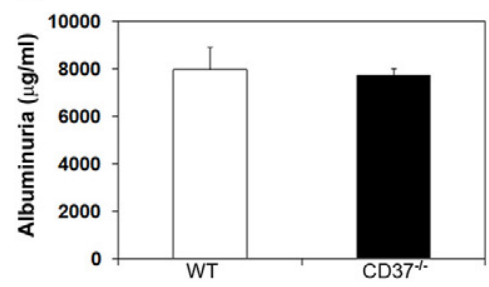

E
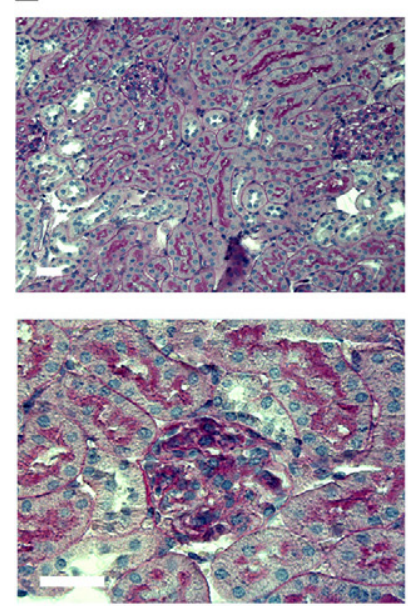

$\mathbf{F}$

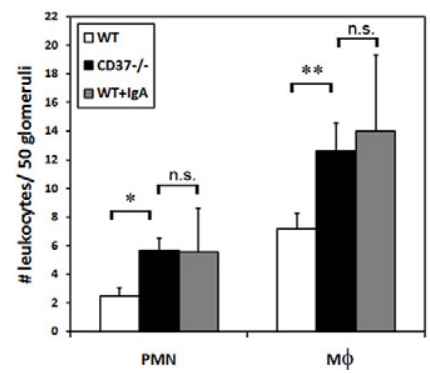

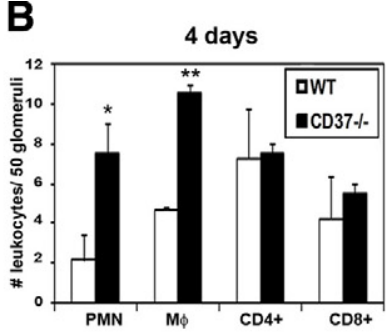

$\mathrm{CD} 37 \%$

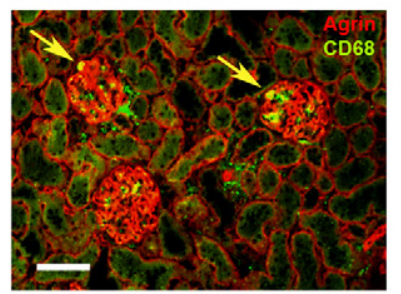

D68

.

.

\section{(a)}

(1)

tion, renal function and histology did not reveal abnor malities in these young $\mathrm{CD} 37^{-1-}$ mice. However, aged $\mathrm{CD} 37^{-1-}$ mice demonstrated, in addition to augmented glomerular IgA deposition, evident renal pathology which was not observed in aged-matched wild-type mice. Severe mesangial proliferation was observed in $\mathrm{CD} 37^{-1-}$ glomeruli that is the common characteristic histopathological finding in IgAN. Our findings correspond to the glomerular IgA deposition seen in the ddY mouse strain, which is a spontaneous murine IgAN model. ${ }^{30,31}$ In ddY mice, the incidence of IgAN is highly variable and high serum IgA levels by itself are not associated with the severity of glomerular injury. However, the presence of serum IgA-IgG2a immune complexes has been correlated with the severity of glomerular lesions. ${ }^{24}$ Interestingly, CD $37^{-1-}$ mice developed high serum levels of both

Figure 5. Increased influx of inflammatory myeloid cells into $\mathrm{CD} 37^{-1}$ glomeruli. Anti-GBM nephritis was induced by injecting $8 \mathrm{mg}$ rabbit antiGBM IgG i.v. in wild-type and $\mathrm{CD} 37^{-/-}$mice. Kidneys were analyzed for inflammation after 2 hours and 4 days. Neutrophil (PMN; GR-1 ${ }^{+}$), macrophage $\left(\mathrm{M} \phi ; \mathrm{CD} 8^{+}\right)$, and $\mathrm{T}$ cell $\left(\mathrm{CD}^{+}, \mathrm{CD}^{+}\right)$influxes were examined in wild-type and $\mathrm{CD} 37^{-1-}$ kidneys by immunohistochemistry. Numbers of leukocytes per 50 glomeruli were quantified 2 hours (A) or 4 days (B) after nephritis induction. $\mathrm{CD} 37^{-/-}$glomeruli contained significantly more influx of neutrophils and macrophages than wild-type glomeruli $\left({ }^{*} P<0.01\right.$, ${ }^{* * *} P<$ $0.001)$. C: Immunohistochemistry stainings of macrophage $\left(\mathrm{CD} 68^{+}\right)$influx (arrows) into wild-type and $\mathrm{CD} 37^{-/-}$glomeruli (visualized by positive staining for agrin) 4 days after nephritis induction. Glomeruli of untreated wild-type and $\mathrm{CD} 37^{-/-}$mice did not contain influx of myeloid or lymphoid cells (not shown). Scale bars represent $60 \mu \mathrm{m}$. D: Albuminuria in wild-type and $\mathrm{CD} 37^{-/-}$mice 4 days after nephritis induction. E: Renal pathology in wild-type (left) and $\mathrm{CD} 37^{-1-}$ (right) mice 4 days after anti-GBM injection was analyzed by histology (Periodic acid-Schiff staining). CD $37^{-/-}$glomeruli showed mild mesangial proliferation (arrow) in contrast to wild-type glomeruli. Scale bars represent $30 \mu \mathrm{m}$. F: Wild-type mice were injected in the tail vein with purified mouse IgA and rabbit anti-mouse GBM IgG. Control age-matched wild-type and $\mathrm{CD} 37^{-/-}$mice were injected i.v. with rabbit anti-mouse GBM IgG only. Kidneys were analyzed for leukocyte influx by immunohistochemistry 4 days after nephritis induction. Numbers of neutrophils (PMN; GR- $1^{+}$) and macrophages $\left(\mathrm{M} \phi\right.$; $\left.\mathrm{CD} 68^{+}\right)$per 50 glomeruli were quantified in kidneys of untreated wild-type and $\mathrm{CD} 37^{-1-}$ mice and wildtype mice treated with IgA. CD $37^{-/-}$glomeruli contained significantly more influx of neutrophils and macrophages than wild-type glomeruli $\left({ }^{*} P<0.02\right.$, $\left.{ }_{* *} P<0.05\right)$, but not more than wild-type glomeruli of mice that received IgA (n.s. indicates nonsignificant). 
IgA-IgG1 and IgA-lgG2a immune complexes during aging, which was not observed in wild-type mice. This suggests that IgA immune complexes play an important role in driving mesangial IgA deposition and renal pathology in $\mathrm{CD} 37^{-1-}$ mice. It has been hypothesized that $\lg \mathrm{A}-$ IgG2 complexes ( $\mathrm{Th}_{1}$ response) mediate glomerular injury by interaction with activatory Fc receptors on macrophages ${ }^{27}$ Taken together, our study demonstrates that $\mathrm{CD} 37^{-1-}$ mice spontaneously develop renal pathology with characteristics of $\lg$ A nephropathy.

We have previously reported that macrophages of $\mathrm{CD}^{-1-}$ mice make increased levels of interleukin-6 (IL-6), ${ }^{9}$ and that the increased IgA response in CD37 ${ }^{-/-}$ mice is dependent on IL-6. IL-6 induces proliferation of mesangial cells in vitro, and a relation between IL-6 levels in urine of IgAN patients and disease progression has been found. ${ }^{32}$ Thus, it is tempting to speculate that high IL-6 levels contribute to renal histopathology in CD37 ${ }^{-1-}$ mice. Because IgAN is triggered under inflammatory conditions, ${ }^{25}$ we determined whether young $\mathrm{CD} 37^{-1-}$ mice were more susceptible to renal damage than wildtype mice during experimental anti-GBM nephritis. The deposition of the injected rabbit anti-mouse GBM IgG, followed by $\mathrm{C} 3 \mathrm{c}$ along the capillary wall, was not affected by CD37-deficiency. However, the humoral immune response against the injected rabbit anti-GBM antibodies was different between wild-type and $\mathrm{CD} 37^{-1-}$ mice. $\mathrm{CD} 37^{-1-}$ mice had markedly higher serum levels of mouse anti-rabbit IgA and glomerular mouse IgA deposits in contrast to wild-type mice. In line with this, CD37 ${ }^{-1-}$ mice showed significantly higher serum $\lg A-\lg \mathrm{G} 1$ and IgA-IgG2a immune complex levels compared with wildtype mice after induction of anti-GBM nephritis.

Analysis of glomerular leukocyte influx demonstrated that recruitment of PMNs and macrophages was increased in $\mathrm{CD} 37^{-1-}$ mice compared with wild-type mice. The importance of IgA in this process was shown in adoptive transfer experiments that revealed that IgA purified from $\mathrm{CD}_{3} 7^{-1-}$ serum was able to exacerbate glomerular inflammation in wild-type mice during anti-GBM nephritis. The polymeric nature of IgA in $\mathrm{CD} 37^{-1-}$ mice may play a pathogenic role in stimulating the glomerular influx of inflammatory leukocytes and development of mesangial proliferative nephritis in these mice. Thus, our data demonstrate that elevated and deposited polymeric IgA by itself is sufficient to enhance the acute anti-GBM induced inflammation by attracting myeloid cells to the glomeruli. However, we do not exclude that CD37-deficiency also increases the intrinsic migratory capacity of CD37 ${ }^{-1-}$ leukocytes since the role of tetraspanins in integrin-mediated migration is well-established. ${ }^{4}$ Surprisingly, CD37 $7^{-1-}$ mice did not show more albuminuria compared with wild-type mice after 4 days, which suggests that albuminuria is not strictly leukocyte-dependent in $\mathrm{CD} 37^{-1-}$ mice with experimental anti-GBM nephritis. Indeed other studies also showed that complement-dependent mechanisms may be operative in anti-GBM nephritis. ${ }^{33}$ Notwithstanding, analysis of renal histology revealed increased mesangial proliferation in $\mathrm{CD}^{-1-}$ glomeruli compared with wild-type glomeruli, supporting a role for
CD37 in initiation of renal pathology during anti-GBM nephritis.

Importantly, two other members of the tetraspanin family, CD63 and CD151, have recently been implicated in preventing renal pathology. CD63-deficient mice have a defect in the collecting duct leading to an altered water balance. ${ }^{34}$ CD151 has been involved in the assembly and maintenance of the GBM structure and plays a key role in integrin-mediated adhesion of podocytes. ${ }^{35,36} \mathrm{Al}$ terations in CD151 are associated with primary glomerular disease in humans and mice. ${ }^{35}$ Thus, tetraspanin proteins CD37, CD151, and CD63 play different nonredundant roles in the biology of the kidney.

In summary, we report that the B cell protein CD37 controls the formation of IgA-containing immune complexes and the glomerular deposition of IgA. Under normal conditions, therefore, tetraspanin CD37 may be protective against the development of IgAN. The absence of CD37 leads to formation of IgA immune complexes in serum, IgA deposition in glomeruli, and subsequently development of mesangial proliferative renal pathology. Moreover, $\mathrm{CD} 37^{-1-}$ mice are more susceptible to renal injury as demonstrated in the anti-GBM nephritis model by an increased influx of inflammatory myeloid cells into glomeruli. This study provides novel insights into immunological mechanism underlying increased IgA production and IgA immune complex formation leading to mesangial deposition during IgAN.

\section{Acknowledgments}

We thank Prof. Dr. Jack Wetzels and Hilde Peters for helpful discussions, Assoc. Prof. Dr. Mark D. Wright for critical reading of the manuscript, and Birgitte OppersWalgreen for help with paraffin embedding of kidneys. Furthermore, we greatly appreciate the technical help from the animal house staff of the Central Animal Facility of the Radboud University Nijmegen Medical Centre.

\section{References}

1. Wright MD, Tomlison MG: The ins and outs of the transmembrane 4 superfamily. Immunol Today 1994, 15:588-594

2. Hemler ME: Tetraspanin functions and associated microdomains. Nat Rev Mol Cell Biol 2005, 6:801-811

3. Charrin S, le Naour F, Silvie O, Milhiet PE, Boucheix C, Rubinstein E: Lateral organization of membrane proteins: tetraspanins spin their web. Biochem J 2009, 420:133-154

4. Berditchevski F: Complexes of tetraspanins with integrins: more than meets the eye. J Cell Sci 2001, 114:4143-4151

5. Wright MD, Moseley GW, van Spriel AB: Tetraspanin microdomains in immune cell signalling and malignant disease. Tissue Antigens 2004 64:533-542

6. Zoller M: Tetraspanins: push and pull in suppressing and promoting metastasis. Nat Rev Cancer 2009, 9:40-55

7. Tarrant JM, Robb L, van Spriel AB, Wright MD: Tetraspanins: molecular organisers of the leukocyte surface. Trends Immunol 2003 24:610-617

8. Levy S, Shoham T: The tetraspanin web modulates immune-signalling complexes. Nat Rev Immunol 2005, 5:136-148

9. Meyer-Wentrup F, Figdor CG, Ansems M, Brossart P, Wright MD, Adema GJ, van Spriel AB: Dectin-1 interaction with tetraspanin CD37 inhibits IL-6 production. J Immunol 2007, 178:154-162 
10. Angelisova P, Hilgert I, Horejsi V: Association of four antigens of the tetraspans family (CD37, CD53, TAPA-1, and R2/C33) with $\mathrm{MHC}$ class II glycoproteins Immunogenetics 1994, 39:249-256

11. Knobeloch KP, Wright MD, Ochsenbein AF, Liesenfeld O, Lohler J, Zinkernagel RM, Horak I, Orinska Z: Targeted inactivation of the tetraspanin CD37 impairs T-cell-dependent B-cell response under suboptimal costimulatory conditions. Mol Cell Biol 2000, 20:5363-5369

12. van Spriel AB, Puls KL, Sofi M, Pouniotis D, Hochrein H, Orinska Z, Knobeloch KP, Plebanski M, Wright MD: A regulatory role for CD37 in T cell proliferation. J Immunol 2004, 172:2953-2961

13. Sheng KC, van Spriel AB, Gartlan KH, Sofi M, Apostolopoulos V, Ashman L, Wright MD: Tetraspanins CD37 and CD151 differentially regulate $\mathrm{Ag}$ presentation and $\mathrm{T}$-cell co-stimulation by DC. Eur $\mathrm{J} \mathrm{Im-}$ munol 2009, 39:50-55

14. van Spriel AB, Sofi M, Gartlan KH, van der Schaaf A, Verschueren I, Torensma R, Raymakers RA, Loveland BE, Netea MG, Adema GJ, Wright MD, Figdor CG: The tetraspanin protein CD37 regulates IgA responses and anti-fungal immunity. PLoS Pathog 2009, 5:e1000338

15. Schena FP, Gesualdo L, Montinaro V: Immunopathological aspects of immunoglobulin A nephropathy and other mesangial proliferative glomerulonephritides. J Am Soc Nephrol 1992, 2:S167-S172

16. Barratt J, Smith AC, Molyneux K, Feehally J: Immunopathogenesis of IgAN. Semin Immunopathol 2007, 29:427-443

17. Couser WG:Glomerulonephritis Lancet 1999, 353:1509-1515

18. Assmann KJ, Tangelder MM, Lange WP, Schrijver G, Koene RA Anti-GBM nephritis in the mouse: severe proteinuria in the heterologous phase. Virchows Arch A Pathol Anat Histopathol 1985 406:285-299

19. Couser WG: Mechanisms of glomerular injury: an overview. Semin Nephrol 1991, 11:254-258

20. Couser WG: Mechanisms of glomerular injury in immune-complex disease. Kidney Int 1985, 28:569-583

21. Rops AL, Gotte M, Baselmans MH, van den Hoven MJ, Steenbergen EJ, Lensen JF, Wijnhoven TJ, Cevikbas F, van den Heuvel LP, van Kuppevelt $\mathrm{TH}$, Berden JH, van der Vlag J: Syndecan-1 deficiency aggravates anti-glomerular basement membrane nephritis. Kidney Int 2007, 72:1204-1215

22. Raats CJ, Bakker MA, Hoch W, Tamboer WP, Groffen AJ, van den Heuvel LP, Berden JH, van den Born J: Differential expression of agrin in renal basement membranes as revealed by domain-specific antibodies. J Biol Chem 1998, 273:17832-17838

23. Roberts IS, Cook HT, Troyanov S, Alpers CE, Amore A, Barratt J, Berthoux F, Bonsib S, Bruijn JA, Cattran DC, Coppo R, D'Agati V, D'Amico G, Emancipator S, Emma F, Feehally J, Ferrario F, Fervenza FC, Florquin S, Fogo A, Geddes CC, Groene HJ, Haas M, Herzenberg AM, Hill PA, Hogg RJ, Hsu SI, Jennette JC, Joh K, Julian BA, Kawamura T, Lai FM, Li LS, Li PK, Liu ZH, Mackinnon B, Mezzano S,
Schena FP, Tomino Y, Walker PD, Wang H, Weening JJ, Yoshikawa $\mathrm{N}$, Zhang $\mathrm{H}$ : The Oxford classification of IgA nephropathy: pathology definitions, correlations, and reproducibility. Kidney Int 2009, 76: 534-545

24. Suzuki $H$, Suzuki $Y$, Aizawa M, Yamanaka T, Kihara M, Pang H, Horikoshi S, Tomino Y: Th1 polarization in murine IgA nephropathy directed by bone marrow-derived cells. Kidney Int 2007, 72:319-327

25. Barratt J, Feehally J: IgA nephropathy. J Am Soc Nephrol 2005 16:2088-2097

26. Schrijver G, Assmann KJ, Bogman MJ, Robben JC, de Waal RM Koene RA: Antiglomerular basement membrane nephritis in the mouse. Study on the role of complement in the heterologous phase. Lab Invest 1988, 59:484-491

27. Rifai A, Millard K: Glomerular deposition of immune complexes prepared with monomeric or polymeric. IgA. Clin Exp Immunol 1985, 60:363-368

28. Chen A, Wong SS, Rifai A: Glomerular immune deposits in experimental IgA nephropathy. A continuum of circulating and in situ formed immune complexes. Am J Pathol 1988, 130:216-222

29. Schena FP, Pastore A, Montinaro $V$ : The role of polymeric IgA in complement-mediated solubilization of IgG and IgA immune complexes. Am J Kidney Dis 1988, 12:433-436

30. Imai H, Nakamoto $Y$, Asakura K, Miki K, Yasuda T, Miura AB: Spontaneous glomerular IgA deposition in ddY mice: an animal model of IgA nephritis. Kidney Int 1985, 27:756-761

31. Miyawaki S, Muso E, Takeuchi E, Matsushima H, Shibata Y, Sasayama S, Yoshida $H$ : Selective breeding for high serum IgA levels from noninbred ddY mice: isolation of a strain with an early onset of glomerular IgA deposition. Nephron 1997, 76:201-207

32. Horii $Y$, Muraguchi A, Iwano M, Matsuda T, Hirayama T, Yamada H, Fujii Y, Dohi K, Ishikawa H, Ohmoto Y: Involvement of IL-6 in mesangial proliferative glomerulonephritis. J Immunol 1989, 143:3949-3955

33. Sheerin NS, Springall T, Carroll MC, Hartley B, Sacks SH: Protection against anti-glomerular basement membrane (GBM)-mediated nephritis in C3- and C4-deficient mice. Clin Exp Immunol 1997, 110:403-409

34. Schroder J, Lullmann-Rauch R, Himmerkus N, Pleines I, Nieswandt B, Orinska Z, Koch-Nolte F, Schroder B, Bleich M, Saftig P: Deficiency of the tetraspanin CD63 associated with kidney pathology but normal Iysosomal function. Mol Cell Biol 2009, 29:1083-1094

35. Baleato RM, Guthrie PL, Gubler MC, Ashman LK, Roselli S: Deletion of CD151 results in a strain-dependent glomerular disease due to severe alterations of the glomerular basement membrane. Am J Pathol 2008, 173:927-937

36. Sachs N, Kreft M, van den Bergh Weerman MA, Beynon AJ, Peters TA, Weening JJ, Sonnenberg A: Kidney failure in mice lacking the tetraspanin CD151. J Cell Biol 2006, 175:33-39 